\title{
Dynamic Analysis for Both Rolling and Climbing of Tri-Star Wheeled Robot
}

\author{
Aye MyaMya Thu ${ }^{\# 1}$, Than Zaw Soe ${ }^{\# 2}$, Tokuji Okada ${ }^{* 3}$ \\ ${ }^{*}$ Mechatronic Engineering Department, Mandalay Technological University, Mandalay, \\ The Republic of the Union of Myanmar \\ "Department of Biocybernetics, Faulty of Engineering, Niigata University, Ikarashi 2-8050, Niigata, Japan
}

\begin{abstract}
An analysis to make the new mechanism design that can climb up a stair is achieved in this paper. Aiming at the functional requirement of climbing the stairs, the dynamics and kinematics during a tri-star wheeled mobile robot's climbing of stairs is studied. To determine the balanced torque and force required for the proposed design, analyses for both rolling and climbing are determined.For both cases, the graphs on the relation of angular displacement and time are determined. To draw the graphs, the method of undetermined coefficient is needed to define the coefficients of complementary solution and particular solution. Kinetic energy and potential energy are introduced to verify the Lagrange equation. Equivalent inertia moment is important to solve the kinetic energy because kinetic means unstable mode and it is the opposite mode of potential energy. Experimental verification with prototype confirms that the new robot can climb up and down the stairs with smooth performance.
\end{abstract}

Keywords: Dynamics analysis, kinematics analysis, mobile robot, stairs climbing ability, tri-star wheel.

\section{Introduction}

In order to gain high mobility on challenging terrains, a mobile robot based on tri-stair wheeled mechanism with locomotion versatility has been proposed. In this paper, one-way bearing aided stair-climbing motion is presented for this tri-star wheeled based robot. The robot can roll on the stair as a traditional wheeled vehicle and also can climb up the stair under the help of its wheels [1]. In contrast, frictional requirements of the one-way bearing aided stair-climbing postures confirm that the robot can climb up the stair with all feasible postures by touching the stair with the tri-star wheels. It verifies the effectiveness of the proposed one-way bearing aided stair-climbing. The climbing ability can be measured by the maximum height of obstacle that the robot is able to travel [2]. Several separated situation during the process of robot climbing is extracted and analyzed respectively [3]. Stairs-climbing is a complicated process for a tri-star wheeled mobile robot under kinematics and dynamics constraints [4]. Lagrange equation based on analytical mechanics focus on derivation with mathematics tools and has more superiority than vector mechanics [5]. When using the differential equation approach, it is found necessary to consider the transition as several sections in series in order to avoid numerical instabilities [6].

On the other hand, second order linear nonhomogeneous equations and corresponding homogeneous equations are proved for calculating particular solution and complementary solution. To get these solutions, it is needed to use the method of undetermined coefficient. The Method of Undetermined Coefficients is a systematic way to determine the general form of the particular solution $\mathrm{Y}(\mathrm{t})$ based on the nonhomogeneous term $\mathrm{g}(\mathrm{t})$ in the given equation. The basic idea is that many of the most familiar and commonly encountered functions have derivatives that vary from their parent functions: exponential, polynomials, sine and cosine [7]. Then the undetermined coefficients method for solving the crisp matrix equation is designed in detail [8]. Base on the linearization analysis, the stability of the equilibrium points is studied. By using the undetermined coefficient method, relationship of angular displacement and time can be formulated by using the graph [9-10].

The remaining of this paper is organized as follows: SectionII describes the process for climbing stairs. In Section III, analysis of the driving mechanism, including analysis for the rolling motion and analysis for the climbing motion is considered in detail. On the other hand, experimental verification for only one set of tri-star wheel is summarized inSection IV. In this section, gear assemblies for both rolling mode and climbing are also described. Finally, conclusion is given in Section V.

\section{Process for Climbing Stairs}

Fig.1 illustrates the proposed motion for climbing stairs. In step 1, wheel "b" touches with the stair and so it gets stuck and makes the whole front part rotates toward the obstacle as shown in step 2. In this stage, wheel "a" contacts with the stair. As the rear part is moving forward, it will push the front part to move along the vertical surface of the stair and finally climb onto the up surface of the stair as shown from step 3 to 4 . The function of movement from step 4 to 5 is similar to the movement from step 1 to 2 . In step 5 , the front part is 
climbing to next step while the rear part is starting contact with the stair. In this situation, the rear part vertically moves along the stair under the pulling forces of the front part as shown from step 6 to 9 . In addition, the rear part motor is also actuated to easily climb the rear part. Step 10 shows that the entire robot is on the top of the stair. In this way, the robot will perform the process of climbing stair.
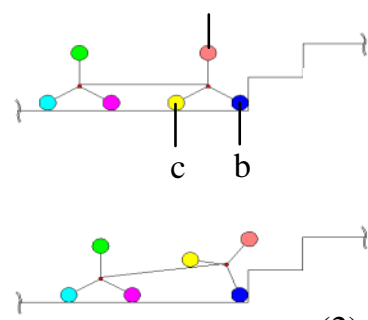

(2)
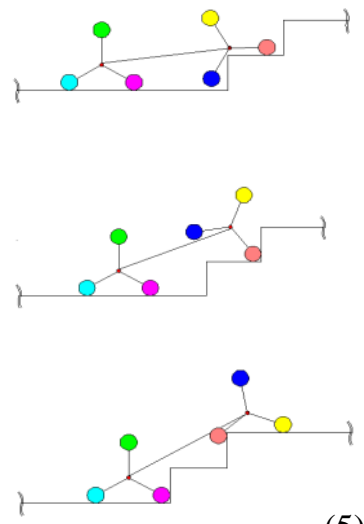

(5)
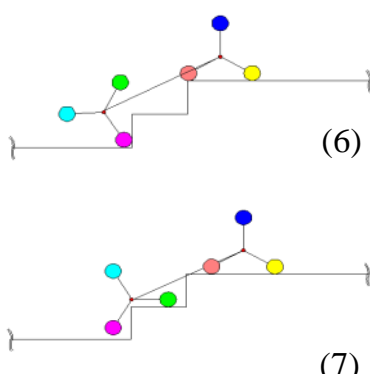

(7)

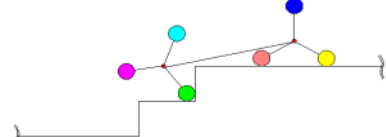

(8)

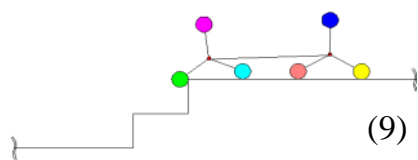

(9)

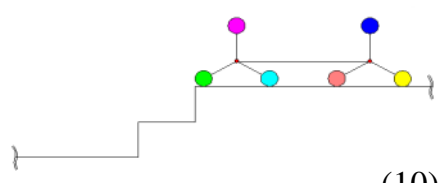

(10)

Figure. 1. Process for climbing stairs

III. Analysis of the Driving Mechanism

This section describes the analysis of the driving mechanism especially the analyses for both rolling and climbing motions. Then the calculations for the tri-star wheeled parameters are included.

\subsection{Analysis of the rolling motion}

Fig. 2 shows that the robot is rolling on the slope surface of an inclination angle $\delta$. This angle $\delta$ will be zero if the robot is rolling on the flat surface.

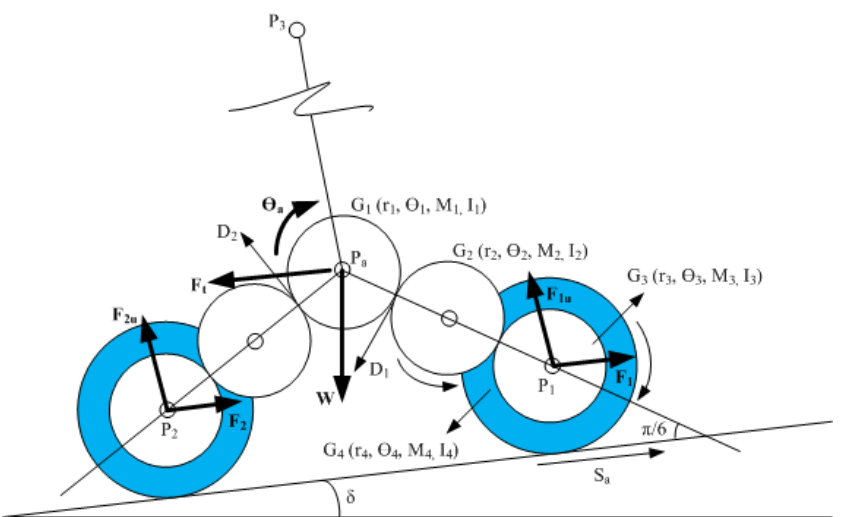

Figure. 2. Rolling motion of the tri-star wheel

In this section, the term of symbols are represented for rolling motion and can be defined as follow: $\mathrm{a}=$ representation for a rolling motion

$\mathrm{Q}_{\mathrm{a}}=\mathrm{CW}$ driving torque of a motor for rolling motion 
$\mathrm{M}_{\mathrm{i}}=$ circular masses of gears including wheels in a rolling mechanism where (i=1 4)

$\theta_{\mathrm{a}}=$ an angular parameter of the gear $\mathrm{G}_{1}$ at $\mathrm{P}_{\mathrm{a}}$

$\theta_{\mathrm{i}}=$ angular displacement of each gear where $(\mathrm{i}=1 \sim 4)$

$\mathrm{I}_{\mathrm{i}}=$ inertial moments around the centre axis of each mass of gear including wheels where (i=1 4)

$r_{i}=$ the radius of the mass $M_{i}$ where $(i=1 \sim 4)$

Suppose that such masses of axial shafts, bearings and wheel support frames are all negligible small.

From Fig. 2, Equivalent inertial momentof the driving shaft at $\mathrm{P}_{\mathrm{a}}$ is:

$\left.\mathrm{I}_{\mathrm{ae}}=\mathrm{I}_{1}+3\left(\mathrm{r}_{1} / \mathrm{r}_{2}\right)^{2} \mathrm{I}_{2}+3\left\{\left(\mathrm{r}_{1} / \mathrm{r}_{2}\right) \mathrm{r}_{2} / \mathrm{r}_{3}\right)\right\}^{2}\left(\mathrm{I}_{3}+\mathrm{I}_{4}\right)(1)$

In a steady condition, robot velocity $(=\mathrm{V})$ is calculated as follow:

$\Delta \theta_{3} / \Delta \theta_{\mathrm{a}}=\mathrm{r}_{1} / \mathrm{r}_{3}(2)$

Rolling distance, $\mathrm{S}_{\mathrm{a}}$, is

$$
\mathrm{S}_{\mathrm{a}}=\mathrm{r}_{4} \theta_{3}
$$

$\mathrm{S}_{\mathrm{a}}$ is the linear motion and it is needed to consider about the angular motion. Therefore,

$\mathrm{V}_{\mathrm{a}}=\mathrm{r}_{4}\left(\mathrm{r}_{1} / \mathrm{r}_{3}\right) \theta_{\mathrm{a}}$

To get the motion energy that is called kinetic energy, the basic formula for kinetic energy is K.E = $\mathrm{MV}^{2} / 2$ and it is needed to add the linear energy and angular energy as the kinetic energy is unstable.Kinetic energy $T_{a}$ can be simplified as follow by inserting $V_{a}=r_{4}\left(r_{1} / r_{3}\right) \cdot \theta_{a}$ in the basic formula of kinetic energy.

$\mathrm{T}_{\mathrm{a}}=\left[\mathrm{I}_{\mathrm{ae}}+\left(\mathrm{M}_{\mathrm{t}}+\mathrm{W}\right)\left\{\mathrm{r}_{4}\left(\mathrm{r}_{1} / \mathrm{r}_{3}\right)\right\}^{2}\right]\left(\theta_{\mathrm{a}}\right)^{2} / 2$

Here, $\mathrm{W}$ is external load operating on the wheel axis and $\mathrm{M}_{\mathrm{t}}$ is the total mass of the wheel mechanism meaning that the sum of the mass of all gears including wheels and it is needed to multiply by three if there is the number of gears or wheels is three. In this way, $\mathrm{M}_{\mathrm{t}}$ can be defined as follow:

$\mathrm{M}_{\mathrm{t}}=\mathrm{M}_{1}+3 \mathrm{M}_{2}+3 \mathrm{M}_{3}+3 \mathrm{M}_{4}+\mathrm{M}_{5}+3 \mathrm{M}_{6}+\mathrm{M}_{7}$

To get the potential energy, the basic formula for potential energy is P.E $=$ Mghand it is not needed to add angular energy as the potential energy is stable unlike with the kinetic energy.Potential energy $U_{a}$ can be simplified as follow by inserting $h=r_{4} \theta_{3} \sin \delta$ and $\theta_{3}=\left(r_{1} / r_{3}\right) \theta_{a}$ in the basic formula of potential energy.

$\mathrm{U}_{\mathrm{a}}=\left(\mathrm{M}_{\mathrm{t}}+\mathrm{W}\right) \mathrm{gr}_{4}\left(\mathrm{r}_{1} / \mathrm{r}_{3}\right) \theta_{\mathrm{a}} \sin \delta$

Lagrange equation is available to get the values of $\theta_{\mathrm{a}}, \theta_{\mathrm{a}}$, and $\theta_{\mathrm{a}}$ :

$\mathrm{L}_{\mathrm{a}}=\mathrm{T}_{\mathrm{a}}-\mathrm{U}_{\mathrm{a}}$

By abstracting potential energy from kinetic energy, Lagrange equation becomes as follow:

where,

$\mathrm{L}_{\mathrm{a}}=\left[\mathrm{I}_{\mathrm{ae}}+\left(\mathrm{M}_{\mathrm{t}}+\mathrm{W}\right)\left\{\mathrm{r}_{4}\left(\mathrm{r}_{1} / \mathrm{r}_{3}\right)\right\}^{2}\right]\left(\theta_{\mathrm{a}}\right)^{2} / 2-\left(\mathrm{M}_{\mathrm{t}}+\mathrm{W}\right) \mathrm{gr}_{4}\left(\mathrm{r}_{1} / \mathrm{r}_{3}\right) \theta_{\mathrm{a}} \sin \delta$

$$
\mathrm{K}_{1}=\mathrm{I}_{\mathrm{ae}}+\left(\mathrm{M}_{\mathrm{t}}+\mathrm{W}\right)\left\{\mathrm{r}_{4}\left(\mathrm{r}_{1} / \mathrm{r}_{3}\right)\right\}^{2}
$$

$\mathrm{K}_{2}=\left(\mathrm{M}_{\mathrm{t}}+\mathrm{W}\right) \operatorname{gr}_{4}\left(\mathrm{r}_{1} / \mathrm{r}_{3}\right) \sin \delta$

Therefore, (9) becomes as follow:

$\mathrm{L}_{\mathrm{a}}=\mathrm{K}_{1}\left(\theta_{\mathrm{a}}^{*}\right)^{2} / 2-\mathrm{K}_{2} \theta_{\mathrm{a}}$

As the robot's velocity is directly proportional to the viscous friction and the torque given from the motor is not fully effective to the robot. Thus, every motion has the energy loss as follow:

where,

$$
\mathrm{q}_{\mathrm{a}}=\mathrm{Q}_{\mathrm{a}}-\mathrm{r}_{4}\left(\mathrm{r}_{1} / \mathrm{r}_{3}\right)\left\{\mathrm{F}_{\mathrm{t}}+\left(\mathrm{M}_{\mathrm{t}}+\mathrm{W}\right) \mathrm{gsin} \delta\right\}-\eta_{\mathrm{a}}\left\{\mathrm{r}_{4}\left(\mathrm{r}_{1} / \mathrm{r}_{3}\right)\left(\mathrm{M}_{\mathrm{t}}+\mathrm{W}\right) \mathrm{g} \sin \delta \theta_{\mathrm{a}}\right\} \quad(11)
$$

$\eta_{\mathrm{a}}=$ constant as an integrated torque loss factor (sec/rad)

$\mathrm{q}_{\mathrm{a}}=$ torque given from the motor

$\mathrm{Q}_{\mathrm{a}}=$ torque received from the robot

$\mathrm{F}_{\mathrm{t}}=$ traction force, wheel tread area on the ground

$K_{3}$ is a symbolic notation for making an analytical description simple and defined as $K_{3}=\eta_{a} \cdot r_{4}\left(r_{1} / r_{3}\right)$

$\left(\mathrm{M}_{\mathrm{t}}+\mathrm{W}\right) \mathrm{gsin} \delta$. Therefore, (11) becomes as follow:

$\mathrm{q}_{\mathrm{a}}=\mathrm{Q}_{\mathrm{a}}-\mathrm{r}_{4}\left(\mathrm{r}_{1} / \mathrm{r}_{3}\right)\left\{\mathrm{F}_{\mathrm{t}}+\left(\mathrm{M}_{\mathrm{t}}+\mathrm{W}\right) \mathrm{g} \sin \delta\right\}-\mathrm{K}_{3} \theta_{\mathrm{a}}$

Noticing that the Lagrange equation in this analysis has only a parameter $\theta_{\mathrm{a}}$ and demonstrates its use by:

$$
\frac{\mathrm{d}}{\mathrm{dt}}\left(\frac{\partial \mathrm{L}_{\mathrm{a}}}{\partial \theta_{\mathrm{a}}^{\square}}\right)-\frac{\partial \mathrm{L}_{\mathrm{a}}}{\partial \theta_{\mathrm{a}}}=\mathrm{q}_{\mathrm{a}}
$$

From (10), non-homogeneous second order differential equation is:

$\mathrm{K}_{1}\left(\theta_{\mathrm{a}}^{*}\right)-\mathrm{K}_{2}=\mathrm{Q}_{\mathrm{a}}-\mathrm{r}_{4}\left(\mathrm{r}_{1} / \mathrm{r}_{3}\right)\left\{\mathrm{F}_{\mathrm{t}}+\left(\mathrm{M}_{\mathrm{t}}+\mathrm{W}\right) g \sin \delta\right\}-\mathrm{K}_{3} \theta_{\mathrm{a}}$

To get the characteristic equation, it is needed to gather the constant values in one side as follow.

where,

$$
\mathrm{K}_{1}\left(\theta_{\mathrm{a}}^{*}\right)+\mathrm{K}_{3} \theta_{\mathrm{a}}=\mathrm{Q}_{\mathrm{a}}+\mathrm{K}_{2}-\mathrm{r}_{4}\left(\mathrm{r}_{1} / \mathrm{r}_{3}\right)\left\{\mathrm{F}_{\mathrm{t}}+\left(\mathrm{M}_{\mathrm{t}}+\mathrm{W}\right) \mathrm{gsin} \delta\right\}
$$

$$
\mathrm{K}_{4}=\mathrm{K}_{2}-\mathrm{r}_{4}\left(\mathrm{r}_{1} / \mathrm{r}_{3}\right)\left\{\mathrm{F}_{\mathrm{t}}+\left(\mathrm{M}_{\mathrm{t}}+\mathrm{W}\right) \mathrm{gsin} \delta\right\}
$$

By simplifying the value of $K_{4}$, (15) becomes as follow:

$$
\mathrm{K}_{1}\left(\theta_{\mathrm{a}}^{-}\right)+\mathrm{K}_{3} \theta_{\mathrm{a}}=\mathrm{Q}_{\mathrm{a}}+\mathrm{K}_{4}
$$

Characteristic equation is: 
Then,

$$
\mathrm{K}_{1} \mathrm{~m}^{2}+\mathrm{K}_{3} \mathrm{~m}=0
$$

$\mathrm{m}_{1}=0$ or $\mathrm{m}_{2}=-\mathrm{K}_{3} / \mathrm{K}_{1} \mathrm{t}$

This leads to suppose the complementary function:

$$
\mathrm{f}_{1}=\mathrm{c}_{1}+\mathrm{c}_{2} \mathrm{e}^{-(\mathrm{K} / \mathrm{K}) \mathrm{t}}
$$

In addition, it can estimate the particular integral by thinking the right part constant of (16):

$$
\mathrm{f}_{2}=\mathrm{c}_{3} \mathrm{t}
$$

Addition of complementary function and particular function gives a complete solution as follow:

$$
\theta_{\mathrm{a}}=\mathrm{c}_{1}+\mathrm{c}_{2} \mathrm{e}^{-(\mathrm{K} / \mathrm{K}) \mathrm{t}}+\mathrm{c}_{3} \mathrm{t}
$$

By using the method of undetermined coefficient under such initial conditions that $\theta_{\mathrm{a}}=0$ and $\theta_{\mathrm{a}}=0$ when $\mathrm{t}=0$. $\theta_{\mathrm{a}}=\left(\mathrm{Q}_{\mathrm{a}}+\mathrm{K}_{4}\right) / \mathrm{K}_{3}\left\{\mathrm{t}-\left(\mathrm{K}_{1} / \mathrm{K}_{3}\right)\left(1-\mathrm{e}_{3}^{-\left(\mathrm{K}_{3} / \mathrm{K}\right) \mathrm{t}}\right)\right\}$

Here, the values of mass and radius of gears/wheels are: $\left(M_{1}, r_{1}\right)=\left(M_{2}, r_{2}\right)=\left(M_{3}, r_{3}\right)=(51.4,22.5)$, $\left(\mathrm{M}_{4}, \mathrm{r}_{4}\right)=(43.5,50),\left(\mathrm{M}_{5}, \mathrm{r}_{5}\right)=(10.4,15),\left(\mathrm{M}_{6}, \mathrm{r}_{6}\right)=(10.7,17.5),\left(\mathrm{M}_{7}, \mathrm{r}_{7}\right)=(283.6,50)$, then $\delta=20 \mathrm{deg}, \mathrm{Q}_{\mathrm{a}}=0.5 \mathrm{kgm}$, $\mathrm{W}=5 \mathrm{~kg}, \mathrm{M}_{\mathrm{t}}=0.816 \mathrm{~kg}$ and $\eta_{\mathrm{a}}=1$.

After substituting the above magnitudes in (22), the relationship between angular displacement $\left(\theta_{\mathrm{a}}\right)$ and time $(\mathrm{t})$ is formulated as follow:

$$
\begin{aligned}
& \theta_{\mathrm{a}}=4.6123\left\{\mathrm{t}-0.1516\left(1-\mathrm{e}^{-6.5947 t}\right)\right\} \\
& \theta_{\mathrm{a}}=4.6123-4.6110 \mathrm{e}^{-6.5947 t}(23 \mathrm{~b}) \\
& \theta_{\mathrm{a}}=30.4082 \mathrm{e}^{-6.5947 t}(23 \mathrm{c})
\end{aligned}
$$

Fig. 3 shows the motion characteristics expressed by (22).

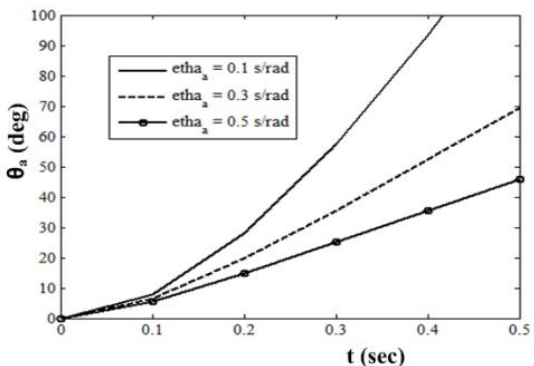

(a)

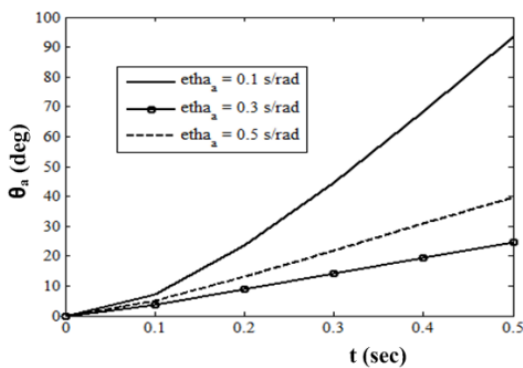

(b)

Figure. 3. Relationship between angular displacement $\left(\theta_{\mathrm{a}}\right)$ and time (t) with (a) $\delta=10 \mathrm{deg}$ and (b) $\delta=$ $20 \mathrm{deg}$. In this case, the unknown parameters can be defined as $\mathrm{W}=5 \mathrm{~kg}, \mathrm{~F}_{\mathrm{t}}=1 \mathrm{~kg}$ and $\mathrm{Q}_{\mathrm{a}}=0.5 \mathrm{kgm}$.

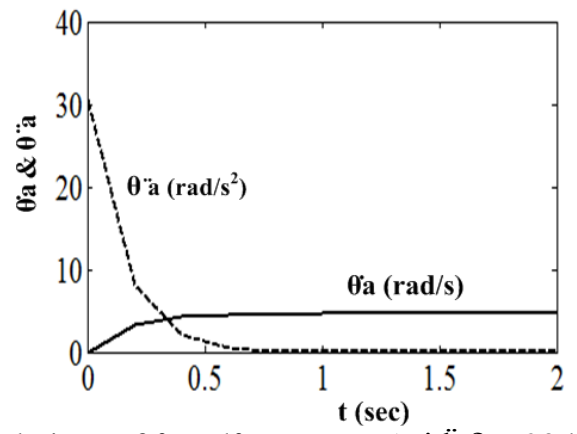

Figure. 4. Relations of $\theta_{\mathrm{a}}$ and $\theta_{\mathrm{a}}$ versus $\mathrm{t}$ (with $\delta=20 \mathrm{deg}$ and $\eta_{\mathrm{a}}=0.1 \mathrm{~s} / \mathrm{rad}$ )

In stationary condition, kinetic analysis for balancing forces on $\mathrm{X}$ and $\mathrm{Y}$ axes:

$$
\mathrm{Q}_{\mathrm{a}}=\mathrm{r}_{1}\left(\mathrm{D}_{1}+\mathrm{D}_{2}+\mathrm{D}_{3}\right)
$$

Here, $D_{1}, D_{2}, D_{3}$ are forces that $Q_{a}$ around $P_{a}$ is transferred by splitting to drive gears $G_{2}$. Notice that $D_{3}$ is negligibly small when compared with $\mathrm{D}_{1}$ and $\mathrm{D}_{2}$ due to no load of traction. Thus,

$$
\mathrm{Q}_{\mathrm{a}} \cong \mathrm{r}_{1}\left(\mathrm{D}_{1}+\mathrm{D}_{2}\right)
$$

Here, $F_{1}=D_{1}\left(r_{3} / r_{4}\right)$ and $F_{2}=D_{2}\left(r_{3} / r_{4}\right)$. Therefore,

where,

$$
\mathrm{Q}_{\mathrm{a}}=\mathrm{r}_{1}\left(\mathrm{r}_{4} / \mathrm{r}_{3}\right)\left(\mathrm{F}_{1}+\mathrm{F}_{2}\right)
$$

$F_{1}, F_{2}=$ forces operating at axial points $P_{1}$ and $P_{2}$

$F_{t}=$ push force from back

For balancing in the rectangular coordinate system:

$$
\left(\mathrm{F}_{1}+\mathrm{F}_{2}\right) \cos \delta=\left(\mathrm{F}_{1 \mathrm{u}}+\mathrm{F}_{2 \mathrm{u}}\right) \sin \delta+\mathrm{F}_{\mathrm{t}} \cos \delta
$$


$\left(\mathrm{F}_{1}+\mathrm{F} 2\right) \sin \delta+\left(\mathrm{F}_{1 \mathrm{u}}+\mathrm{F}_{2 \mathrm{u}}\right) \cos \delta=\mathrm{W}+\mathrm{F}_{\mathrm{t}} \sin \delta$

However, the balance of $\mathrm{D}_{1}$ and $\mathrm{D}_{2}$ does not matter in the equally configured tri-star wheel mechanism. Then elimination of the term $\mathrm{F}_{1 \mathrm{u}}+\mathrm{F}_{2 \mathrm{u}}$ from (26) and (27) yields

$\mathrm{F} 1+\mathrm{F} 2=\mathrm{Ft}+\mathrm{W} \sin \delta$

Therefore, $(25)$ is rewritten as follows:

$\mathrm{Q}_{\mathrm{a}}=\mathrm{r}_{1}\left(\mathrm{r}_{4} / \mathrm{r}_{3}\right)\left(\mathrm{F}_{\mathrm{t}}+\mathrm{W} \sin \delta\right)$

(26) and(27) are utilized to get the values of $\mathrm{F}_{1}+\mathrm{F}_{2}$ and $\mathrm{F}_{1 \mathrm{u}}+\mathrm{F}_{2 \mathrm{u}}$ by assigning $\delta, \mathrm{W}$ and $\mathrm{F}_{\mathrm{t}}$. Also, the necessary torque $Q_{a}$ versus $\delta$ is calculated by assigning $r_{1}=r_{3}=2.25 \mathrm{~cm}, r_{4}=5 \mathrm{~cm}, F_{t}=5 \mathrm{~kg}$ and W=3kg.

$\mathrm{Q}_{\mathrm{a}}=0.05(5+3 \sin \delta)$

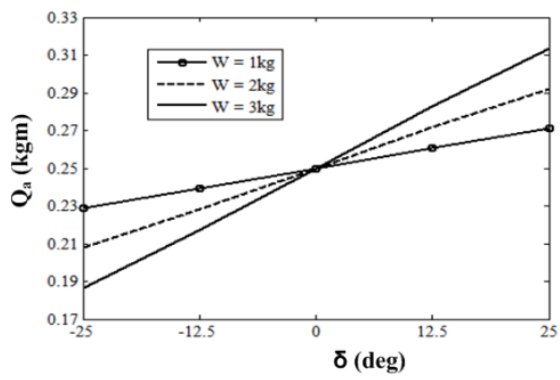

Figure. 5 Relation of $\mathrm{Q}_{\mathrm{a}}$ versus $\delta$ to make a stationary standing on a slope (with $\mathrm{F}_{\mathrm{t}}=5 \mathrm{~kg}, \mathrm{r}_{1}=2.25 \mathrm{~cm}$, $\left.\mathrm{r}_{4} / \mathrm{r}_{3}=5.0 / 2.25\right)$

Fig. 5 clearly shows that $\mathrm{Q}_{\mathrm{a}}$ is almost proportional to $\delta$ when the slope angle is within \pm 25 degree. Of course, $\mathrm{Q}_{\mathrm{a}}$ is bigger when $\mathrm{W}$ is bigger.

\subsection{Analysis of the climbing motion}

Fig. 6 shows that the robot is climbing on the slope surface of an inclination angle $\delta$. In the staircase, the slope surface will be the stairs but the climbing condition will be the same. Angle $\beta$ represents the angular shift from the rolling mode to climbing mode.

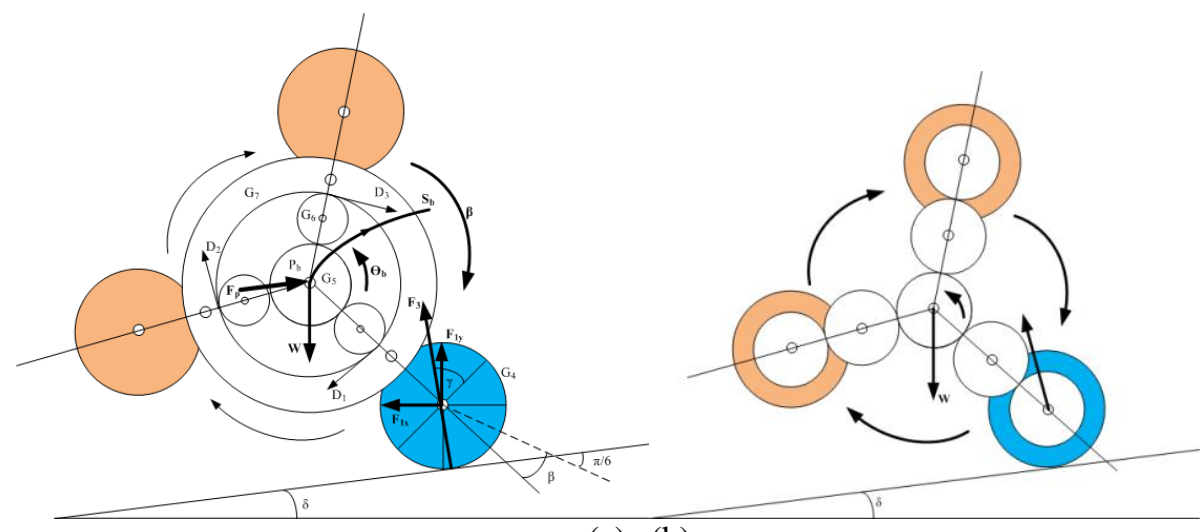

(a) (b)

Figure. 6. Climbing motion of the tri-star wheel: (a) Climbing motion of inner gear, (b) Free condition of rolling mechanism when climbing by the $\mathrm{CCW}$ driving

In this section, the term of symbols are represented for climbing motion and can be defined as follow:

$\mathrm{b}=$ representation for a climbing motion

$\mathrm{Q}_{\mathrm{b}}=\mathrm{CCW}$ driving torque of a motor for climbing motion

$\mathrm{M}_{\mathrm{i}}=$ masses of gears assembled in a climbing mechanism where (i=5 7)

$\theta_{\mathrm{b}}=$ an angular parameter of the gear $\mathrm{G}_{5}$ at $\mathrm{P}_{\mathrm{b}}$

$\theta_{\mathrm{i}}=$ angular displacement of each gear where $(\mathrm{i}=5 \sim 7)$

$I_{i}=$ inertial moments around the centre axis of each mass of gear where (i=5 7)

$r_{i}=$ the radius of the mass $M_{i}$ where $(i=5 \sim 7)$

Suppose that such masses of axial shafts, bearings and wheel support frames are all negligible small.

From Fig. 6, Equivalent inertial momentof the driving shaft at $\mathrm{P}_{\mathrm{b}}$ is:

$$
I_{b e}=I_{5}+3\left(r_{5} / r_{6}\right)^{2} I_{6}+3\left\{\left(r_{5} / r_{6}\right)\left(r_{6} / r_{7}\right)\right\}^{2}\left(I_{7}+I_{c t}\right)
$$


where,

$\mathrm{I}_{7}=$ inertial moment of the gear $\mathrm{G}_{7}$ including three gears $\mathrm{G}_{6}$ around $\mathrm{P}_{\mathrm{b}}$

$I_{c t}=$ sum of inertial moments of masses $M_{1}, M_{2}, M_{3}$, and $M_{4}$ rotating with the inner gear $\mathrm{G}_{7}$

$$
\begin{aligned}
& \mathrm{I}_{\mathrm{c} 1}=\mathrm{I}_{1} \quad(32 \mathrm{a}) \\
& \mathrm{I}_{\mathrm{c} 2}=3 \mathrm{M}_{2}\left(\mathrm{r}_{1}+\mathrm{r}_{2}\right)^{2} \quad(32 \mathrm{~b}) \\
& \mathrm{I}_{\mathrm{c} 3}=3 \mathrm{M}_{3}\left(\mathrm{r}_{1}+2 \mathrm{r}_{2}+\mathrm{r}_{3}\right)^{2} \\
& \mathrm{I}_{\mathrm{c} 4}=3 \mathrm{M}_{4}\left(\mathrm{r}_{1}+2 \mathrm{r}_{2}+\mathrm{r}_{3}\right)^{2}
\end{aligned}
$$

Therefore, Equivalent inertial momentof the driving shaft at $\mathrm{P}_{\mathrm{b}}$ becomes:

$$
\mathrm{I}_{\mathrm{be}}=\mathrm{I}_{5}+3\left(\mathrm{r}_{5} / \mathrm{r}_{6}\right)^{2} \mathrm{I}_{6}+3\left(\mathrm{r}_{5} / \mathrm{r}_{7}\right)^{2}\left(\mathrm{I}_{7}+\mathrm{I}_{\mathrm{c} 1}+\mathrm{I}_{\mathrm{c} 2}+\mathrm{I}_{\mathrm{c} 3}+\mathrm{I}_{\mathrm{c} 4}\right)
$$

Here, it is needed to consider about the distance of $\mathrm{G}_{1}, \mathrm{G}_{2}$ and $\mathrm{G}_{3}$ in the climbing motion because they are rotating together with the rotation of inner gear. Therefore, climbing distance, $S_{b}$, is

where,

$$
\mathrm{S}_{\mathrm{b}}=\left(\mathrm{r}_{1}+2 \mathrm{r}_{2}+\mathrm{r}_{3}\right)\left(\mathrm{r}_{5} \theta_{\mathrm{b}}\right) / \mathrm{r}_{7}
$$

$$
\beta=\left(r_{5} \theta_{b}\right) / r_{7}
$$

$\mathrm{S}_{\mathrm{b}}$ is the linear motion and it is needed to consider about the angular motion. Therefore,

$$
\mathrm{V}_{\mathrm{b}}=\left(\mathrm{r}_{1}+2 \mathrm{r}_{2}+\mathrm{r}_{3}\right)\left(\mathrm{r}_{5} / \mathrm{r}_{7}\right) \theta_{\mathrm{b}}
$$

To get the motion energy that is called kinetic energy, the basic formula for kinetic energy is K.E = $\mathrm{MV}^{2} / 2$ and it is needed to add the linear energy and angular energy as the kinetic energy is unstable. Kinetic energy $T_{b}$ can be simplified as follow by inserting $V_{b}=\left(r_{1}+2 r_{2}+r_{3}\right)\left(r_{5} / r_{7}\right) \theta_{b}$ in the basic formula of kinetic energy.

$\mathrm{T}_{\mathrm{b}}=\left[\mathrm{I}_{\mathrm{be}}+\left(\mathrm{M}_{\mathrm{t}}+\mathrm{W}\right)\left\{\left(\mathrm{r}_{1}+2 \mathrm{r}_{2}+\mathrm{r}_{3}\right)\left(\mathrm{r}_{5} / \mathrm{r}_{7}\right)\right\}^{2}\right]\left(\theta_{\mathrm{b}}\right)^{2} / 2$

To get the potential energy, the basic formula for potential energy is P.E $=$ Mghand it is not needed to add angular energy as the potential energy is stable unlike with the kinetic energy. Potential energy $U_{b}$ can be simplified as follow by inserting $h=\left(r_{1}+2 r_{2}+r_{3}\right)\left\{\sin (\beta+\pi / 6-\delta)-\sin (\pi / 6-\delta)\right.$ and $\beta=\left(r_{5} / r_{7}\right) \theta_{b}$ in the basic formula of potential energy.

$\left.\mathrm{U}_{\mathrm{b}}=\left(\mathrm{M}_{\mathrm{t}}+\mathrm{W}\right) \mathrm{g}\left(\mathrm{r}_{1}+2 \mathrm{r}_{2}+\mathrm{r}_{3}\right)\left[\sin \left\{\left(\mathrm{r}_{5} / \mathrm{r}_{7}\right) \theta_{\mathrm{b}}+\pi / 6-\delta\right)\right\}-\sin (\pi / 6-\delta)\right]$

Definition of $h$ in (37) is shown in Fig. 7.

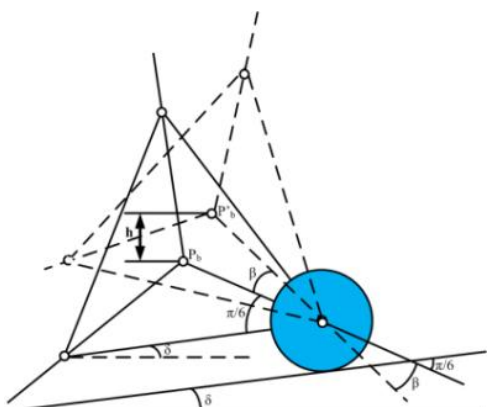

Figure. 7. Definition of $\mathrm{h}$

Lagrange equation is available to get the values of $\theta_{\mathrm{b}}, \theta_{\mathrm{b}}$, and $\theta_{\mathrm{b}}$ :

$\mathrm{L}_{\mathrm{b}}=\mathrm{T}_{\mathrm{b}}-\mathrm{U}_{\mathrm{b}}(38)$

By abstracting potential energy from kinetic energy, Lagrange equation becomes as follow:

where,

$$
\left.\mathrm{L}_{\mathrm{b}}=\mathrm{I}_{\mathrm{be}}\left(\theta_{\mathrm{b}}\right)^{2} / 2+\left(\mathrm{M}_{\mathrm{t}}+\mathrm{W}\right)\left\{\left(\mathrm{r}_{1}+2 \mathrm{r}_{2}+\mathrm{r}_{3}\right)\left(\mathrm{r}_{5} / \mathrm{r}_{7}\right) \theta_{\mathrm{b}}\right\}^{2} / 2-\left(\mathrm{M}_{\mathrm{t}}+\mathrm{W}\right) \mathrm{g}\left(\mathrm{r}_{1}+2 \mathrm{r}_{2}+\mathrm{r}_{3}\right)\left[\sin \left\{\left(\mathrm{r}_{5} / \mathrm{r}_{7}\right) \theta_{\mathrm{b}}+\pi / 6-\delta\right)\right\}-\sin (\pi / 6-\delta)\right]
$$

$$
\begin{aligned}
& \mathrm{K}_{5}=\mathrm{I}_{\mathrm{be}}+\left(\mathrm{M}_{\mathrm{t}}+\mathrm{W}\right)\left\{\left(\mathrm{r}_{1}+2 \mathrm{r}_{2}+\mathrm{r}_{3}\right)\left(\mathrm{r}_{5} / \mathrm{r}_{7}\right)\right\}^{2} \\
& \mathrm{~K}_{6}=\left(\mathrm{M}_{\mathrm{t}}+\mathrm{W}\right) \mathrm{g}\left(\mathrm{r}_{1}+2 \mathrm{r}_{2}+\mathrm{r}_{3}\right) \quad(39 \mathrm{~b}) \\
& \mathrm{K}_{7}=\mathrm{K}_{6} \sin (\pi / 6-\delta)
\end{aligned}
$$

Therefore, (37) becomes as follow:

$\mathrm{L}_{\mathrm{b}}=\mathrm{K}_{5}\left(\theta_{\mathrm{b}}\right)^{2} / 2-\mathrm{K}_{6} \sin \left\{\left(\mathrm{r}_{5} / \mathrm{r}_{7}\right) \theta_{\mathrm{b}}\right\} \cos (\pi / 6-\delta)-\mathrm{K}_{7} \cos \left\{\left(\mathrm{r}_{5} / \mathrm{r}_{7}\right) \theta_{\mathrm{b}}\right\}+\mathrm{K}_{7}$

In addition, $\theta_{\mathrm{b}}$ may be boosted by an external push force $\mathrm{F}_{\mathrm{p}}$ given by the rear wheel unit. The torque by push,

say $\mathrm{Q}_{\mathrm{bp}}$, operating on the shaft at $\mathrm{P}_{\mathrm{b}}$ is:

$\mathrm{Q}_{\mathrm{bp}}=\left(\mathrm{r}_{5}\left(\mathrm{r}_{1}+2 \mathrm{r}_{2}+\mathrm{r}_{3}\right) /\left(\mathrm{r}_{1}+2 \mathrm{r}_{2}+\mathrm{r}_{3}-\mathrm{r}_{7}\right)\right) \mathrm{F}_{p} \sin \gamma$

As the robot's velocity is directly proportional to the viscous friction and the torque given from the motor is not fully effective to the robot. Thus, every motion has the energy loss as follow:

where,

$$
\mathrm{q}_{\mathrm{b}}=\mathrm{Q}_{\mathrm{b}}+\mathrm{Q}_{\mathrm{bp}}-\eta_{\mathrm{b}}\left(\mathrm{r}_{1}+2 \mathrm{r}_{2}+\mathrm{r}_{3}\right)\left(\mathrm{r}_{5} / \mathrm{r}_{7}\right) \theta_{\mathrm{b}}
$$

$\eta_{\mathrm{b}}=$ constant as an integrated torque loss factor $(\mathrm{kgs})$

$\mathrm{q}_{\mathrm{b}}=$ torque given from the motor 
$\mathrm{Q}_{\mathrm{b}}=$ torque received from the robot

$\mathrm{K}_{8}$ is a symbolic notation for making an analytical description simple and defined as $\mathrm{K}_{8}=\eta_{\mathrm{b}}$ $\left(r_{1}+2 r_{2}+r_{3}\right)\left(r_{5} / r_{7}\right)$. Therefore, (40) becomes as follow:

$\mathrm{q}_{\mathrm{b}}=\mathrm{Q}_{\mathrm{b}}+\mathrm{Q}_{\mathrm{bp}}-\mathrm{K}_{8} \theta_{\mathrm{b}}$

Noticing that the Lagrange equation in this analysis has only a parameter $\theta_{\mathrm{b}}$ anddemonstrates its use by:

$\frac{\mathrm{d}}{\mathrm{dt}}\left(\frac{\partial \mathrm{L}_{\mathrm{b}}}{\partial \theta_{\mathrm{b}}}\right)-\frac{\partial \mathrm{L}_{\mathrm{b}}}{\partial \theta_{\mathrm{b}}}=\mathrm{q}_{\mathrm{b}}$

From (40), non-homogeneous second order differential equation is:

$\mathrm{K}_{5}\left(\theta_{\mathrm{b}}\right)-\mathrm{K}_{6} \cos (\pi / 6-\delta)\left(\mathrm{r}_{5} / \mathrm{r}_{7}\right) \cos \left\{\left(\mathrm{r}_{5} / \mathrm{r}_{7}\right) \theta_{\mathrm{b}}\right\}+\mathrm{K}_{7}\left(\mathrm{r}_{5} / \mathrm{r}_{7}\right) \sin \left\{\left(\mathrm{r}_{5} / \mathrm{r}_{7}\right) \theta_{\mathrm{b}}\right\}=\mathrm{Q}_{\mathrm{b}}+\mathrm{Q}_{\mathrm{bp}}-\mathrm{K}_{8} \theta_{\mathrm{b}}(45)$

where,

$\mathrm{K}_{9}=\mathrm{K}_{6}\left(\mathrm{r}_{5} / \mathrm{r}_{7}\right) \cos (\pi / 6-\delta)$

$\mathrm{K}_{10}=\mathrm{K}_{7}\left(\mathrm{r}_{5} / \mathrm{r}_{7}\right)$

Therefore,

$\mathrm{K}_{5}(\theta \ddot{\mathrm{b}})-\mathrm{K}_{9} \cos \left\{\left(\mathrm{r}_{5} / \mathrm{r}_{7}\right) \theta_{\mathrm{b}}\right\}+\mathrm{K}_{10} \sin \left\{\left(\mathrm{r}_{5} / \mathrm{r}_{7}\right) \theta_{\mathrm{b}}\right\}=\mathrm{Q}_{\mathrm{b}}+\mathrm{Q}_{\mathrm{bp}}-\mathrm{K}_{8} \theta_{\mathrm{b}}(48)$

To get the characteristic equation, it is needed to gather the constant values in one side as follow.

$\mathrm{K}_{5}\left(\theta_{\mathrm{b}}\right)+\mathrm{K}_{8} \theta_{\mathrm{b}}=\mathrm{Q}_{\mathrm{b}}+\mathrm{Q}_{\mathrm{bp}}+\mathrm{K}_{9} \cos \left\{\left(\mathrm{r}_{5} / \mathrm{r}_{7}\right) \theta_{\mathrm{b}}\right\}-\mathrm{K}_{10} \sin \left\{\left(\mathrm{r}_{5} / \mathrm{r}_{7}\right) \theta_{\mathrm{b}}\right\}$

At this moment, trigonometric functions in (49) are expressed as Taylor series since the value of $\left(\mathrm{r}_{5} / \mathrm{r}_{7}\right) \theta_{\mathrm{b}}$ is assumed to be nearly equal to zero in the start position. That is, $\cos \left\{\left(\mathrm{r}_{5} / \mathrm{r}_{7}\right) \theta_{\mathrm{b}}\right\}$ and $\sin \left\{\left(\mathrm{r}_{5} / \mathrm{r}_{7}\right) \theta_{\mathrm{b}}\right.$ are estimated to be 1 and $\left(\mathrm{r}_{5} / \mathrm{r}_{7}\right) \theta_{\mathrm{b}}$, respectively. Then, (49) is written as:

$\mathrm{K}_{5}\left(\theta_{\mathrm{b}}\right)+\mathrm{K}_{8} \theta_{\mathrm{b}}+\mathrm{K}_{10}\left(\mathrm{r}_{5} / \mathrm{r}_{7}\right) \theta_{\mathrm{b}}=\mathrm{Q}_{\mathrm{b}}+\mathrm{Q}_{\mathrm{bp}}+\mathrm{K}_{9}$

Characteristic equation is:

$\mathrm{K}_{5} \mathrm{~m}^{2}+\mathrm{K}_{8} \mathrm{~m}+\mathrm{K}_{10}\left(\mathrm{r}_{5} / \mathrm{r}_{7}\right)=0$

And the characteristic solutions $\mathrm{m}_{1}$ and $\mathrm{m}_{2}$ are determined depending on the value of

$\lambda=\mathrm{K}^{2}{ }_{8}-4 \mathrm{~K}_{5} \mathrm{~K}_{10}\left(\mathrm{r}_{5} / \mathrm{r}_{7}\right)$

In the tri-star mechanism, $\lambda$ becomes negative in general. And the solutions are conjugate complex numbers $\mathrm{p} \pm \mathrm{qi}$.

Therefore, the complementary function is

$\theta_{\mathrm{b}}=\mathrm{e}^{\mathrm{pt}}\left\{\mathrm{c}_{4} \cos (\mathrm{qt})+\mathrm{c}_{5} \sin (\mathrm{qt})\right\}$

Also, the particular integral $c_{6}$ can be estimated by considering the right part of (50) is only a constant to form a complete solution:

where,

$$
\theta_{\mathrm{b}}=\mathrm{e}^{\mathrm{pt}}\left\{\mathrm{c}_{4} \cos (\mathrm{qt})+\mathrm{c}_{5} \sin (\mathrm{qt})\right\}+\mathrm{c}_{6}
$$

$\mathrm{c}_{4}=-\left(\mathrm{Q}_{\mathrm{b}}+\mathrm{Q}_{\mathrm{bp}}+\mathrm{K}_{9}\right) /\left\{\mathrm{K}_{10}\left(\mathrm{r}_{5} / \mathrm{r}_{7}\right)\right\}$

$\mathrm{c}_{5}=(\mathrm{p} / \mathrm{q}) \cdot\left(\mathrm{Q}_{\mathrm{b}}+\mathrm{Q}_{\mathrm{bp}}+\mathrm{K}_{9}\right) /\left\{\mathrm{K}_{10}\left(\mathrm{r}_{5} / \mathrm{r}_{7}\right)\right\}$

$\mathrm{c}_{6}=\left(\mathrm{Q}_{\mathrm{b}}+\mathrm{Q}_{\mathrm{bp}}+\mathrm{K}_{9}\right) /\left\{\mathrm{K}_{10}\left(\mathrm{r}_{5} / \mathrm{r}_{7}\right)\right\}$ when $\mathrm{t}=0$ :

By using the method of undetermined coefficient under such initial conditions that $\theta_{\mathrm{b}}=0$ and $\theta_{\mathrm{b}}=0$

$$
\theta_{\mathrm{b}}=\left(\mathrm{Q}_{\mathrm{b}}+\mathrm{Q}_{\mathrm{bp}}+\mathrm{K}_{9}\right) /\left\{\mathrm{K}_{10}\left(\mathrm{r}_{5} / \mathrm{r}_{7}\right)\right\}\left[1-\mathrm{e}^{\mathrm{pt}}\{\cos (\mathrm{qt})-(\mathrm{p} / \mathrm{q}) \sin (\mathrm{qt})\}\right]
$$

Here, the values of mass and radius of gears/wheels are: $\left(\mathrm{M}_{1}, \mathrm{r}_{1}\right)=\left(\mathrm{M}_{2}, \mathrm{r}_{2}\right)=\left(\mathrm{M}_{3}, \mathrm{r}_{3}\right)=(51.4,22.5),\left(\mathrm{M}_{4}, \mathrm{r}_{4}\right)=$ $(43.5,50),\left(\mathrm{M}_{5}, \mathrm{r}_{5}\right)=(10.4,15),\left(\mathrm{M}_{6}, \mathrm{r}_{6}\right)=(10.7,17.5),\left(\mathrm{M}_{7}, \mathrm{r}_{7}\right)=(283.6,50), \eta_{\mathrm{b}}=1, \mathrm{Q}_{\mathrm{b}}=1 \mathrm{kgm}$.

After substituting the above magnitudes in (56), the relationship between angular displacement $\left(\theta_{b}\right)$ and time (t) is formulated as $(57 \mathrm{a})$.

$\theta_{\mathrm{b}}=31.305\left[1+\mathrm{e}^{-2.6726 t}\{-\cos (2.9626 \mathrm{t})-0.9021 \sin (2.9626 \mathrm{t})\}\right]$
$\left.\theta_{\mathrm{b}}=\mathrm{e}^{-2.6726 \mathrm{t}}\{0.001919 \cos (2.9626 \mathrm{t})+168.2184 \sin (2.9626 \mathrm{t})\}\right]$
$\left.\left.\theta_{\mathrm{b}}=\mathrm{e}^{-2.6726 t} 498.3587 \cos (2.9626 \mathrm{t})-449.5861 \sin (2.9626 \mathrm{t})\right\}\right]$

Fig. 8 shows the motion characteristics expressed by (56)

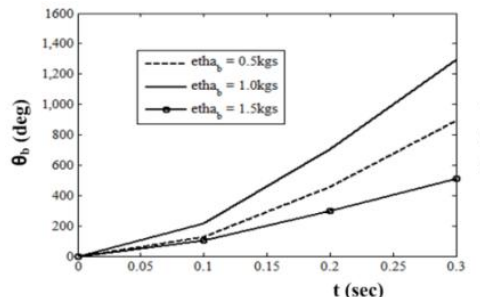

(a)

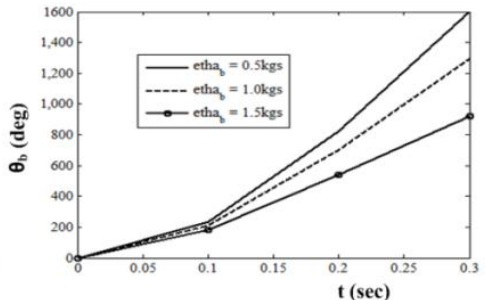

(b)

Figure. 8. Relationship between angular displacement $\left(\theta_{b}\right)$ and time (t) with (a) $\mathrm{Q}_{\mathrm{b}}=1 \mathrm{kgm}$ and (b) $\mathrm{Q}_{\mathrm{b}}=$ $3 \mathrm{kgm}$. In this case, the unknown parameters can be defined as $\delta=20 \mathrm{deg}, \mathrm{W}=5 \mathrm{~kg}$ then $\eta_{\mathrm{b}}$ and $\mathrm{Q}_{\mathrm{b}}$ are considered as variables. 


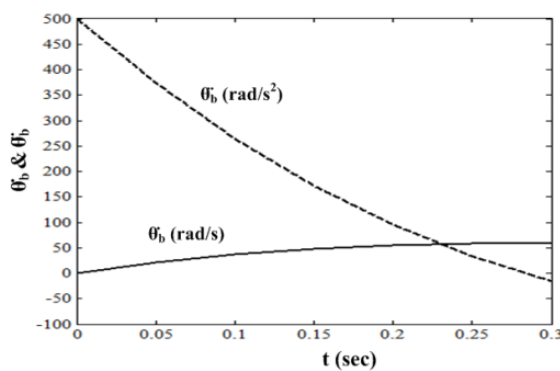

Figure. 9. Relations of $\theta_{\mathrm{b}}$ and $\theta_{\mathrm{b}}$ versus $\mathrm{t}$ (with $\delta=20 \mathrm{deg}$ and $\eta_{\mathrm{b}}=1.0 \mathrm{kgs}$ )

In stationary condition, kinetic analysis for balancing forces on $\mathrm{X}$ and $\mathrm{Y}$ axes:

$\mathrm{Q}_{\mathrm{b}}=\mathrm{r}_{5}\left(\mathrm{D}_{1}+\mathrm{D}_{2}+\mathrm{D}_{3}\right)$

(58)

Here, $D_{1}, D_{2}, D_{3}$ are forces that $Q_{b}$ around $P_{b}$ is transferred by splitting to drive gears $G_{6}$. Notice that $D_{2}$ and $\mathrm{D}_{3}$ are negligibly small when compared with $\mathrm{D}_{1}$ due to no load of traction. Therefore,

$\mathrm{Q}_{b} \cong \mathrm{r}_{5} \mathrm{D}_{1}(59)$

The torque balance around $\mathrm{P}_{\mathrm{b}}$ :

where,

$\left(r_{5}+r_{6}\right) D_{1}=\left(r_{1}+2 r_{2}+r_{3}\right) F_{3} \cos \gamma$

$\gamma=\pi / 6+\beta$

Therefore, $(60)$ becomes:

$\left(\mathrm{r}_{5}+2 \mathrm{r}_{6}\right) \mathrm{D}_{1}=\left(\mathrm{r}_{1}+2 \mathrm{r}_{2}+\mathrm{r}_{3}\right) \mathrm{F}_{3} \cos (\pi / 6+\beta)$

Definition of $\gamma$ in (61) is shown in Fig. 10.

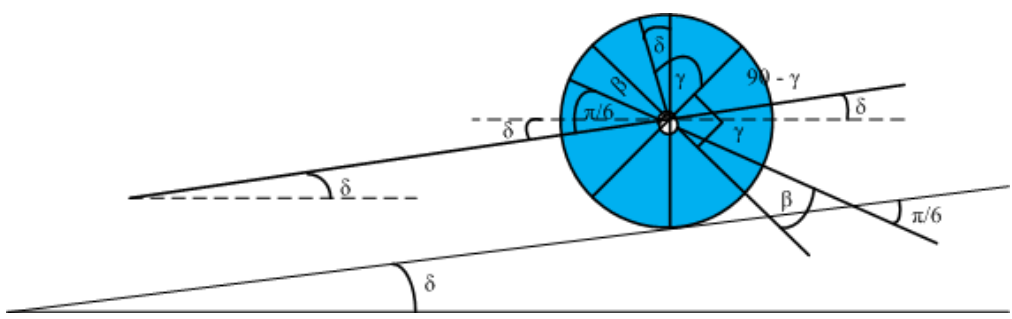

Figure. 10. Definition of $\gamma$

For balancing in the rectangular coordinate system:

From $\mathrm{X}$ component of $\mathrm{F}_{3}$ and $\mathrm{F}_{\mathrm{p}}$ :

$$
-\mathrm{F}_{3} \sin \delta+\mathrm{F}_{\mathrm{p}} \cos \delta=0
$$

From $\mathrm{Y}$ component of $\mathrm{F}_{3}, \mathrm{~F}_{\mathrm{p}}$, and $\mathrm{W}$ :

$\mathrm{F}_{3} \cos \delta+\mathrm{F}_{\mathrm{p}} \sin \delta=\mathrm{W}$

(59) to (63) are utilized to get the values of unknown parameters $\mathrm{Q}_{\mathrm{b}}, \mathrm{D}_{1}, \mathrm{~F}_{\mathrm{p}}$ and $\mathrm{F}_{3}$ by assigning $\mathrm{W}$, uniquely. From (61),

$$
\mathrm{F}_{3}=\left[\left(\mathrm{r}_{5}+2 \mathrm{r}_{6}\right) \mathrm{D}_{1}\right] /\left[\left(\mathrm{r}_{1}+2 \mathrm{r}_{2}+\mathrm{r}_{3}\right) \cos (\pi / 6+\beta)\right]
$$

Let $X=\left[\left(r_{1}+2 r_{2}+r_{3}\right) \cos (\pi / 6+\beta)\right]$

Substitute (64) in (62)

From (59),

$$
-\left(\mathrm{r}_{5}+2 \mathrm{r}_{6}\right) \mathrm{D}_{1} \sin \delta+\mathrm{F}_{\mathrm{p}} \mathrm{X} \cos \delta=0
$$

Substitute $\mathrm{D}_{1}=\mathrm{Q}_{\mathrm{b}} / \mathrm{r}_{5}$ in $(65)$

$$
\begin{aligned}
& -\left(\mathrm{r}_{5}+2 \mathrm{r}_{6}\right)\left(\mathrm{Q}_{\mathrm{b}} / \mathrm{r}_{5}\right) \sin \delta+\mathrm{F}_{\mathrm{p}} \mathrm{X} \cos \delta=0 \\
& -\mathrm{Q}_{\mathrm{b}}\left[1+\left(2 \mathrm{r}_{6} / \mathrm{r}_{5}\right)\right] \sin \delta+\mathrm{F}_{\mathrm{p}} \mathrm{X} \cos \delta=0
\end{aligned}
$$

Substitute (64) in (63)

$$
\left(\mathrm{r}_{5}+2 \mathrm{r}_{6}\right) \mathrm{D}_{1} \cos \delta+\mathrm{F}_{\mathrm{p}} \mathrm{X} \sin \delta=\mathrm{WX}
$$

Substitute $\mathrm{D}_{1}=\mathrm{Q}_{\mathrm{b}} / \mathrm{r}_{5}$ in $(67)$

$\left(\mathrm{r}_{5}+2 \mathrm{r}_{6}\right)\left(\mathrm{Q}_{\mathrm{b}} / \mathrm{r}_{5}\right) \cos \delta+\mathrm{F}_{\mathrm{p}} \mathrm{X} \sin \delta=\mathrm{WX}$

$\mathrm{Q}_{b}\left[1+\left(2 \mathrm{r}_{6}, \mathrm{r}_{5}\right)\right] \cos \delta+\mathrm{F}_{\mathrm{p}} \mathrm{X} \sin \delta=\mathrm{WX}$

Actually, elimination of $F_{3}$ in (62) and (63) gives two equations of two unknown parameters of $Q_{b}$ and $F_{p}$.

$$
\begin{aligned}
& \mathrm{e}_{11} \mathrm{Q}_{\mathrm{b}}+\mathrm{e}_{12} \mathrm{~F}_{\mathrm{p}}=\mathrm{e}_{13} \\
& \mathrm{e}_{21} \mathrm{Q}_{\mathrm{b}}+\mathrm{e}_{22} \mathrm{~F}_{\mathrm{p}}=\mathrm{e}_{23}
\end{aligned}
$$

By comparing with (66) and (69) 


$$
\begin{aligned}
& \mathrm{e}_{11}=-\left[1+\left(2 \mathrm{r}_{6} \mathrm{r}_{5}\right)\right] \sin \delta \\
& \mathrm{e}_{12}=\mathrm{X} \text { os } \delta \\
& \mathrm{e}_{13}=0
\end{aligned}
$$

By comparing with (68) and (70)

$$
\begin{aligned}
& \mathrm{e}_{21}=\left[1+\left(2 \mathrm{r}_{6} \mathrm{r}_{5}\right)\right] \cos \delta \\
& \mathrm{e}_{22}=\mathrm{X} \sin \delta \\
& \mathrm{e}_{23}=\mathrm{WX}
\end{aligned}
$$

These are utilized to have the values of $Q_{b}$ and $F_{p}$. This means that $Q_{b}$ is determined in any posture of $\beta$ depending on $F_{p}$ on the slope having the angle $\delta$.

From (59) and (61)

Here,

$$
\mathrm{Q}_{\mathrm{b}}=\mathrm{r}_{5}\left(\mathrm{r}_{1}+2 \mathrm{r}_{2}+\mathrm{r}_{3}\right) /\left(\mathrm{r}_{5}+2 \mathrm{r}_{6}\right) \mathrm{F}_{3} \cos (\pi / 6+\beta)
$$

Therefore,

$$
\begin{aligned}
& \mathrm{F}_{\mathrm{p}}=\mathrm{W} \sin \delta \\
& \mathrm{F}_{3}=\mathrm{W} \cos \delta
\end{aligned}
$$

$\mathrm{Q}_{\mathrm{b}}=\mathrm{r}_{5}\left(\mathrm{r}_{1}+2 \mathrm{r}_{2}+\mathrm{r}_{3}\right) /\left(\mathrm{r}_{5}+2 \mathrm{r}_{6}\right) \mathrm{W} \cos \delta \cos (\pi / 6+\beta) \quad(71)$

It is clear that $F_{p}$ is constant without any relation of $\beta$. Fig. 11 shows calculated relations of $Q_{a}$ versus $\beta$ depending on $\delta$ in (71).

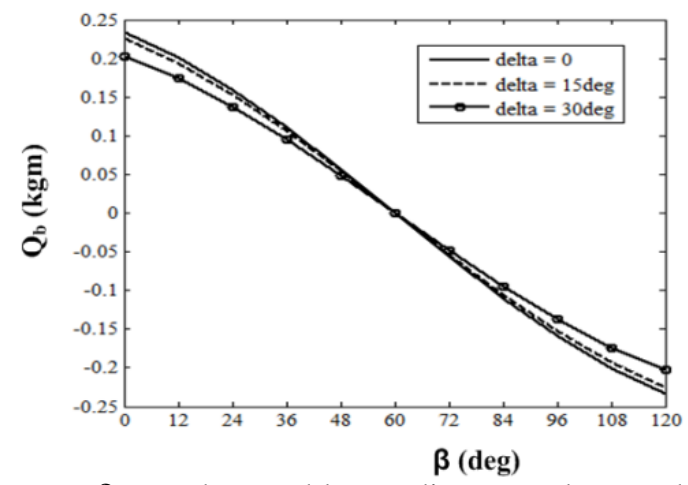

Figure. 11 Relation of $\mathrm{Q}_{\mathrm{b}}$ versus $\delta$ to make a stable standing on a slope under fixed values of $\mathrm{W}=10 \mathrm{~kg}$, $\mathrm{r}_{1}=\mathrm{r}_{2}=\mathrm{r}_{3}=2.25 \mathrm{~cm}, \mathrm{r}_{4}=5.0 \mathrm{~cm}, \mathrm{r}_{5}=1.5 \mathrm{~cm}, \mathrm{r}_{6}=1.75 \mathrm{~cm}$.

The curves in the figure are reasonable to explain the climbing motion, actually. The necessary torque $\mathrm{Q}_{\mathrm{b}}$ is same on slopes of angle $\pm \delta$. Such characteristics that $\mathrm{Q}_{\mathrm{b}}$ becomes minus are suitable to switch the motion from climbing to rolling because the range $\beta>60 \mathrm{deg}$ comes after climbable maximum height of stairs, in general.

\section{Experimental Verification for One Set of Tri-Star Wheel}

The prototype for one set of tri-star wheel is implemented. The proposed robot can climb the maximum height of $14 \mathrm{~cm}$. The experimental verification of the prototype is shown in Fig. 12.
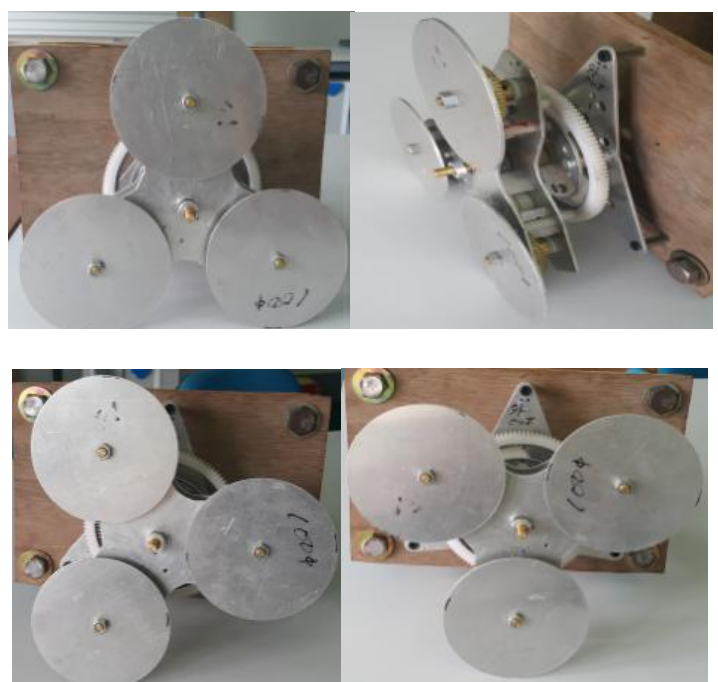

Figure. 12. Experimental verification of the prototype 
In this experiment, only the operations of the gear arrangement for rolling and climbing are specialized. Therefore, this prototype is not connected with the gear motor.

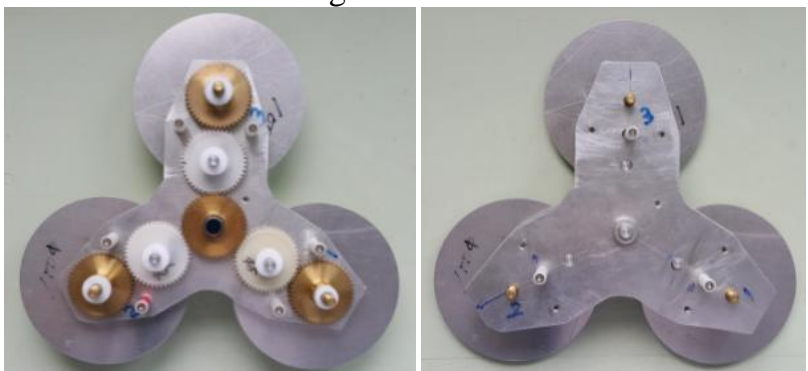

Figure. 13. Gear assembly for rolling motion

If the shaft is turned in clockwise direction, the sun gear that is linked with the shaft will rotate in clockwise direction and three idler gears will rotate in counter-clockwise direction. Thus, three planetary gears will rotate in clockwise direction and as a result the robot will perform the rolling motion. In this condition, Yframe will not rotate because of the locking function of one-way bearing that is implemented inside the sun gear of the inner gear. In this way the robot will perform forward driving and backward driving movements depending on the rotation of the gear motor. The arrangement of gears for the rolling motion is shown in Fig. 13.

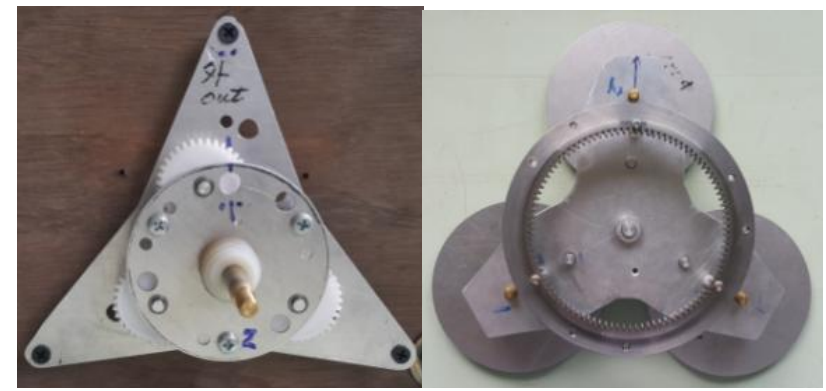

Figure. 14. Gear assembly for climbing motion

If the shaft is turned in counter-clockwise direction, the sun gear that is linked with the shaft will rotate in clockwise direction and three idler gears will rotate in counter-clockwise direction. Thus, the inner will rotate the same direction of three idler gears in clockwise direction and as a result the robot will perform the climbing motion. In this condition, tri-star wheel will not rotate because of the locking function of one-way bearing that is implemented inside the sun gear of the planetary gearbox. In this way the robot will perform climbing up and climbing down movements depending on the rotation of the gear motor. The arrangement of gears for the climbing motion is shown in Fig. 14. Turning right and turning left movements can also perform if four sets of tri-star wheels are implemented.

\section{Conclusions}

This paper presented the analyses for both rolling mode and climbing modes in detail. For both cases, the inclination angle is considered as the angle $\delta$ and it will be changed depending on the use of stair. Additionally, the calculation of the tri-star wheeled parameters is also described. Depending on these parameters, experimental verification for only one set of tri-star wheel and the arrangements of gears for both rolling and climbing are verified. In this prototype, only the operations of spur gears and inner gear are specialized. Therefore, it has not verified with the connection of gear motors. In order to implement gear motors, one gear motor will be needed for each set of tri-star wheeled robot. Thus, four gear motors will be needed for the whole vehicle. With the arrangement of four sets of tri-star wheels, it can perform six modes of movements: forward driving, backward driving, climbing up, climbing down, turning right and turning left. This proposed robot can be used in real world applications such as climbing over the uneven terrain for rescue, military operation, security monitoring, exploration of dangerous environments, de-mining and other works.

\section{Acknowledgements}

The author wishes to acknowledge to the teachers of Department of Mechatronic Engineering in Mandalay Technological University, for their patience, accomplished guidance, sharing fruitful ideas, helpful suggestions, continuous supervision and encouragement during a long period of this paper. The author would like to express her indebtedness and deep gratitude to her beloved parents, for their kind support and 
understanding during the whole course. With this paper, the author has to hold one in honors to all her teachers teaching from kindergarten to University.

Finally, the author wishes to express her gratitude to all those who were directly or indirectly involved towards the successful completion of this paper.

\section{References}

[1]. Yi Sun; Yang Yang; Shugen Ma; HuayanPu, "Modeling paddle aided stair-climbing for a mobile robot based on eccentric paddle mechanism”, Intelligent Robots and Systems (IROS), 2015 IEEE/RSJ International Conference, pp. 4153 - 4158, 2015.

[2]. PattaramonTantichattanont; SzathysSongschon; SathapornLaksanacharoen, "Quasi-static analysis of a leg-wheel hybrid vehicle for enhancing stair climbing ability”, Robotics and Biomimetics, 2007. ROBIO 2007.IEEE International Conference, pp. 1601 - 1605, 2007.

[3]. PegnwenXiong; Aiguo Song; PengJi; Xinjing Huang, "Study on ability of a mobile tracked robot for stair-climbing based on static analysis", Cyber Technology in Automation, Control, and Intelligent Systems (CYBER), 2015 IEEE International Conference, pp. $1327-1332,2015$

[4]. Jinguo Liu; Yuechao Wang; Shugen Ma; Bin Li, "Analysis of stairs-climbing ability for a tracked reconfigurable modular robot", IEEE International Safety, Security and Rescue Rototics, Workshop, pp.36 - 41, 2005.

[5]. Lijuan Zhang; YaqingTu, "Research of Car Inverted Pendulum Model Based on LagrangeEquation",2006 6th World Congress on Intelligent Control and Automation, pp. 820 - 824, 2006.

[6]. W. A. Huting; K. J. Webb, "Comparison of mode-matching and differential equation techniques in the analysis of waveguide transitions", IEEE Transactions on Microwave Theory and Techniques, pp. 280 - 286,1991.

[7]. Zachary S Tseng, Second Order Linear Nonhomogeneous Differential Equations; Method of Undetermined Coefficients, 2012.

[8]. Xiao-Bin Guo; Zeng-Tai Gong, "Undetermined coefficients method for solving semi-fuzzy matrix equations", 2010 International Conference on Machine Learning and Cybernetics, pp. 596 - 600, 2010.

[9]. Xia Wang; Jianping Li; Jianyin Fang, "Si'lnikov Chaos of a 3-D quadratic autonomous system with a four-wing chaotic attractor", Control Conference (CCC), 2011 30th Chinese, pp. 561 - 565, 2011.

[10]. C. Ray Wylie, McGraw-Hill, Linear Differential Equations with Constant CoefficientAdvanced Engineering Mathematics, 1951 . 